\title{
A Multimodal Assignment That Enriches Literacy Learning The Problem
}

\author{
Tim Oldakowski, EdD \\ Assistant Professor of English \\ Slippery Rock University
}

\begin{abstract}
In education the linguistic is the mode most commonly assessed because it is important for students to write clear, complex pieces to show their understanding of content. However, in worlds outside of classrooms additional modes, such as visual, aural, and digital are often used to convey messages. This article demonstrates the value of multimodal learning (the use of more than one mode) as a means for student expression, specifically in responding to young adult literature. Here, I share how students had rich interpretations of a text through the use multiple modes.
\end{abstract}

In the spring of 2013 I was preparing to teach two sections of ENGL 210: Interpreting Literature, a course required by all students at the university where I teach. It was my second year teaching at the university. In my first year, I realized that not all students in the course have an affinity for reading, interpreting, analyzing, and writing about literature. Many of my students were apprehensive about taking a required literature course and weren't hesitant to say so in a diagnostic essay. Many of my students that first year admitted that they didn't like to read, period. However, I noticed the literacy practices of students before, after, and in-between classes. They were texting. They were on their phones looking up information. They were talking about Facebook. They told me how they Googled everything that interested them. They frequently went to websites like YouTube and Funnyordie which revolve around short, created and re-mixed videos. They talked about Twitter. It was then that I realized that students didn't dislike reading, rather that they were experiencing reading in multimodal ways, completely different from the approach educators commonly take in the classroom.

Because I have always been fascinated with assessments that are outside the box, I decided that this was my opportunity to teach these 70 students how to interpret, analyze, and think about literature in a new and innovative way, and that they just might have some fun along the way, too. Thus I introduced the assignment called The Multimodal Analysis of Literary Elements in 'Feed'.

\section{Multimodal Assessment}

Ever since I was a child, I was fascinated when I could respond to an academic task via a creative assignment. I took the opportunity to build a volcano instead of writing about one. My friend and I dressed up like Greek gods and goddesses and took photographs instead of taking a quiz. Even my junior research paper, on the teen films of the 1980's, featured photographs of members of the infamous Brat Pack. What I didn't know some 27 years ago was that I was a multimodal thinker.

Multimodality-meaning that is made through multiple representations and communication systems (Kress \& Van Leeuwen, 2001)-allows individuals to use more than one mode to express understanding. Traditionally, schools focus on one mode-the linguistic. In school, there are verbal lectures, written papers, a myriad of tests and quizzes that ask students to answer questions, and oral presentations where students read from a Power Point. This tradition is typically upheld in the college setting. Not that these types of assessment aren't important, as they are. 
But what happens when students are able to express themselves through more than one mode? What happens when students can respond with modes that extend beyond the linguistic?

It was Pierce (1934) who first explored the world of semiotics, or sign systems as a means of expression or communication. Since then, there have been multiple modes from which one can communicate. Be it oral, gestural, visual, spatial, or digital, there are multiple ways to send messages in this day and age, especially in a world where technology is a primary means for communication. If literacy is being redefined to include ways of knowing that extend beyond print (Dalton \& Procotor, 2008; Leu \& Kinzer, 2000), then it is evident that this new definition of literacy should be integral to teaching. While it's important to value language and for students to read and write, it is also urgent that we provide our students with means of communication that represent real-world ways of thinking, or what Brian Street (1984) calls "New Literacy Studies." The use of multiple modes in learning doesn't replace reading and writing; it enhances these skills through a combination of approaches.

Multimodality relies on transmediation, where individuals transfer "information from one sign system to another" (Suhor, 1984, p. 250). When they do this, the individual has more means, or modes, from which to communicate the message. Because my past students struggled with sharing their interpretations of a text in a traditional paper, I thought I would first use the opportunity to allow them to express their thinking multimodally, as this supports Vygotsky's notion of the Zone of Proximal Development (1986) where students increase their ability to perform difficult tasks through scaffolding led by the instructor. I predicted that by first responding to individually chosen literary elements of the text in a multimodal manner, students would become more articulate and provide deeper analysis of literary elements in subsequent papers. This was the case as I saw the class' median grade on the next two written analyses improve. This assignment suggested that students first mastered the skill of interpretation by choosing literary elements of their choice, and by presenting them multimodally, in a way that they could relate to the text.

A large misconception, however, in multimodal assessment is that the work requires the use of digital tools or technology. While many multimodal artifacts are created via digital tools, such as YouTube, Twitter, Vine, and Instagram, and although many artifacts make use of music, images, or hypertext, the notion of using more modes can include means that do not require technology. A collage made up of pictures cut out of magazines, for instance, constitutes the visual mode without the use of technology or digital tools. This was expressed to my students as they began work on their projects. While I invited them to use technology in their development of interpretations, I stressed that they had to use more than one mode, be it digital or other.

\section{The Project: Analysis of Literary Elements in Feed}

Students began reading M.T. Anderson's Feed, a popular young adult novel that takes place in the distant future. This dystopian setting revolves around the protagonist Titus and his friends, all of whom have feeds implanted in their brains that allow them to passively receive information, primarily from corporations. On a trip to the moon, Titus meets and develops a liking for Violet, another teenager. As the story develops, problematic circumstances arise for Violet as she tries to teach Titus and the other teens to resist the feed.

In each class period, the required section of the text was read and we engaged daily in discussion by responding to interpretive questions that students developed both in small groups and as a whole class. In addition to the questions, I asked students to consider the literary elements that stood out to them in each section. I reviewed the major literary elements, such as theme, symbol, conflict, character, setting, motif, as well as an array of others as we read the text. I didn't want to simply list and define these, as I wanted the students to understand 
elements of literature in context. The Multimodal Analysis of Literary Elements in 'Feed' served as the final assignment after six class discussions on the text.

Before I presented my students with their project, I shared with them the definition of multimodality as well as told them about the value of this type of assessment. For example, I shared with them the work of Bailey (2009), who found that her students increased their knowledge of literary components through song analysis, and that Rozema's (2007) students

The results of students' work was impressive and ranged from projects that were created with little or no technology to projects that took full advantage of technological affordances. scripted and planned more analytical analyses of texts as they created podcasts in which they analyzed the book Feed (Anderson, 2002), which we were reading that semester. I then provided students with the instructions for "The Multimodal Analysis of Literary Elements in Feed."

I asked the students to choose any six literary elements that stood out to them (such as character, theme, symbol, conflict, motif, plot, etc.) and for each to "describe how the element is portrayed in the text followed by an analysis of that element." Each description and analysis was required to be about a substantial paragraph of about 150 words. The students could not simply write these though, as they were asked to present them in a "multimodal format." I gave students examples of multimodal formats ranging from creating soundtracks to emphasize key plot points, to making scrapbooks for major or minor characters, to making a Twitter account for a character. The students eagerly began to think about creative and multimodal ways they could build their projects. Lastly, I asked students to type a one to two page rationale when they completed the project, in which they justified their choices of elements as well as answered the following question: "How did thinking multimodally help shape your thinking about this project?" The results of students' work was impressive and ranged from projects that were created with little or no technology to projects that took full advantage of technological affordances.

\section{Multimodal Projects That Used No Technology}

It was evident that students understood that multimodal projects required more than one mode, but that they didn't necessarily have to have a technological mindset. Drew's project (all names are pseudonyms), for example, was simply a series of drawings of main characters and themes in the text. These vibrant and colorful projects were drawn on cardstock, with the description and analysis on the back of the card. One of the most impressive of these was a drawing of a young woman, with what looked like cuts all over her face (see Figure 1).

Figure 1

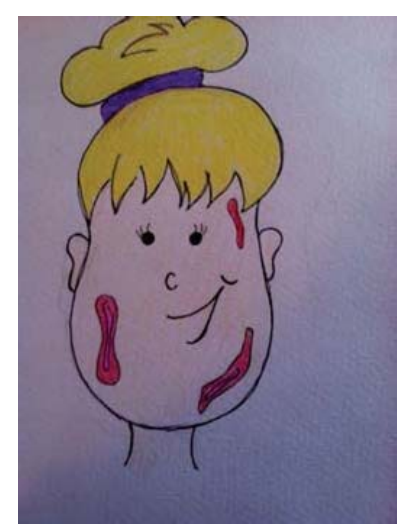

This was done to represent the lesions, hideous scars, which were a major fad acquired by the characters in the text that made these characters seem hip or cool. Drew felt that this was one of the most important elements in the text and wrote that these lesions "represented passivity in the story." She continued to describe the lesions as "wounds" that none of the characters questioned, but rather sought out. She then compared this passivity of acquiring the wounds with the passivity that the main characters developed towards the corporations in the novel.

Another creative multimodal project that required no technology was Frankie's clipboard (see Figure 2), which contained hospital reports on the character of Violet, who became physically ill throughout the book 
because she resisted the feed. Because there were six instances in which the level of Violet's feed was reported, Frankie made a realistic hospital report in which she provided a rich character analysis that not only summarized what had happened to the character, but provided information that relied on her inferences about the character as well.

\section{Figure 2}

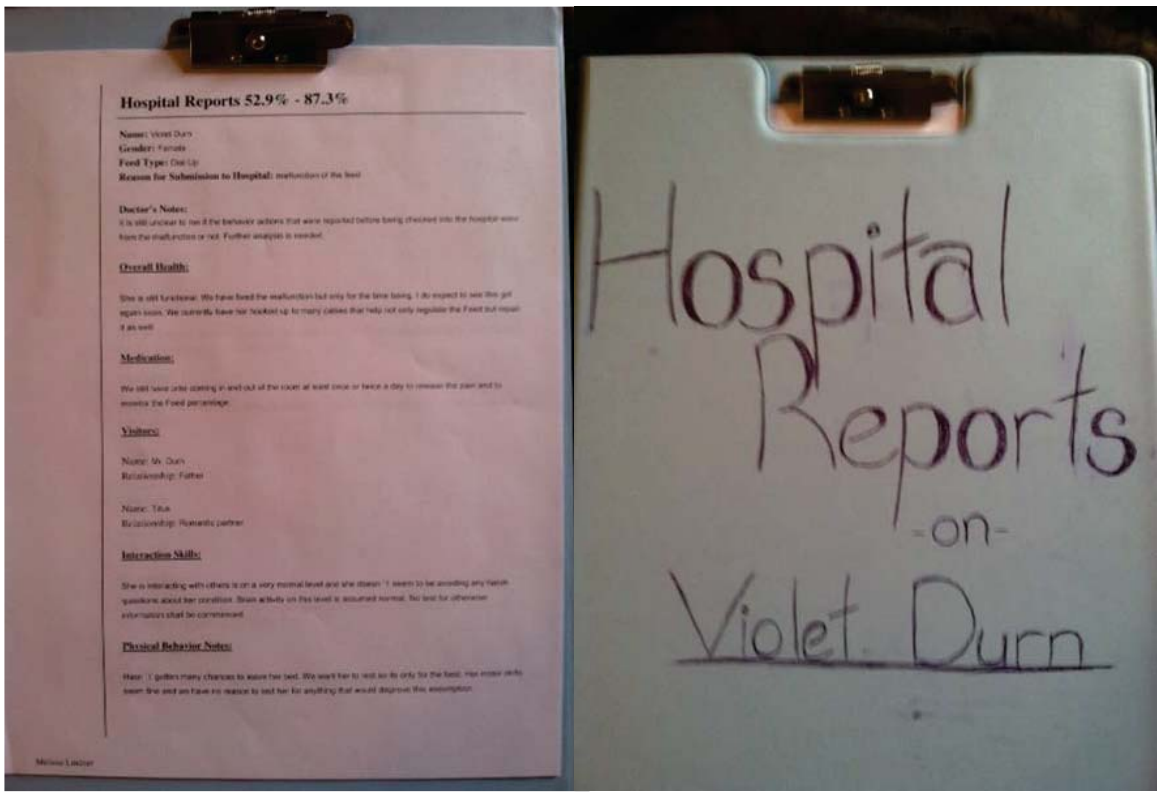

One of the most inventive multimodal projects was created by Dallas. His "Feed-wich" (see Figure 3) was a sandwich made out of construction paper, with each ingredient serving as a metaphor for an element of the text.

\section{Figure 3}

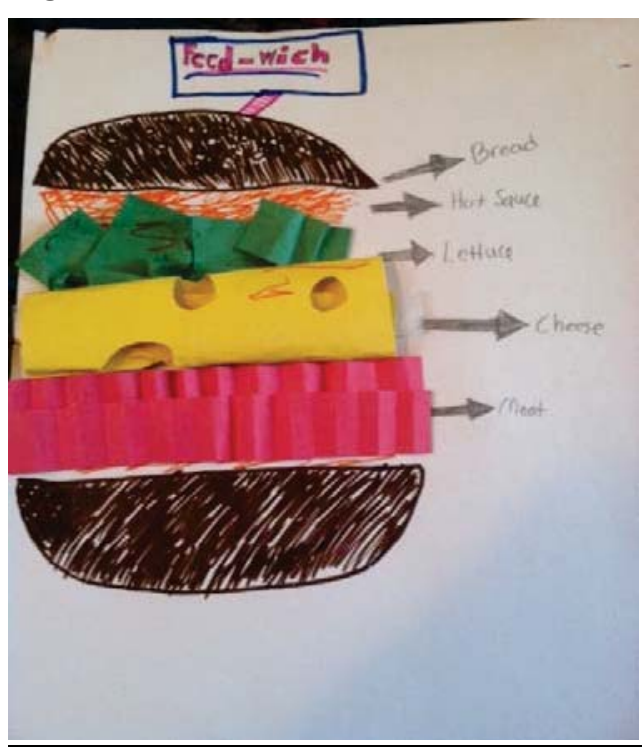

Austin recalled the fable from childhood that the moon was made out of cheese, so he associated the cheese on the "feed-wich" with the moon. The moon was the setting when the story began, and it is also where Dallas explained that the main characters learned how "humans have trashed Earth's natural satellite and turned it into a center of consumerism." This metaphor allowed Dallas to explain that the setting of the moon was important, because it "shows that the domination of advertising exceeds earth's atmosphere." Rather than stating that the moon was the setting, Dallas went into deeper analysis of the setting. 


\section{Multimodal Projects That Minimally Used Technology}

The next level of multimodal projects required technology, but only in their creation, not in their presentation. A fine example of this was Mia's Playbill for the "play" Feed, based on the novel. Mia created a replication of a Broadway Playbill that one might receive when they see a staged performance. For her six elements, Mia wrote about the characters and chose actors that she felt represented those characters as she visualized them in the book. However, Mia went a step beyond when she created the first page of her playbill (see Figure 4).

\section{Figure 4}

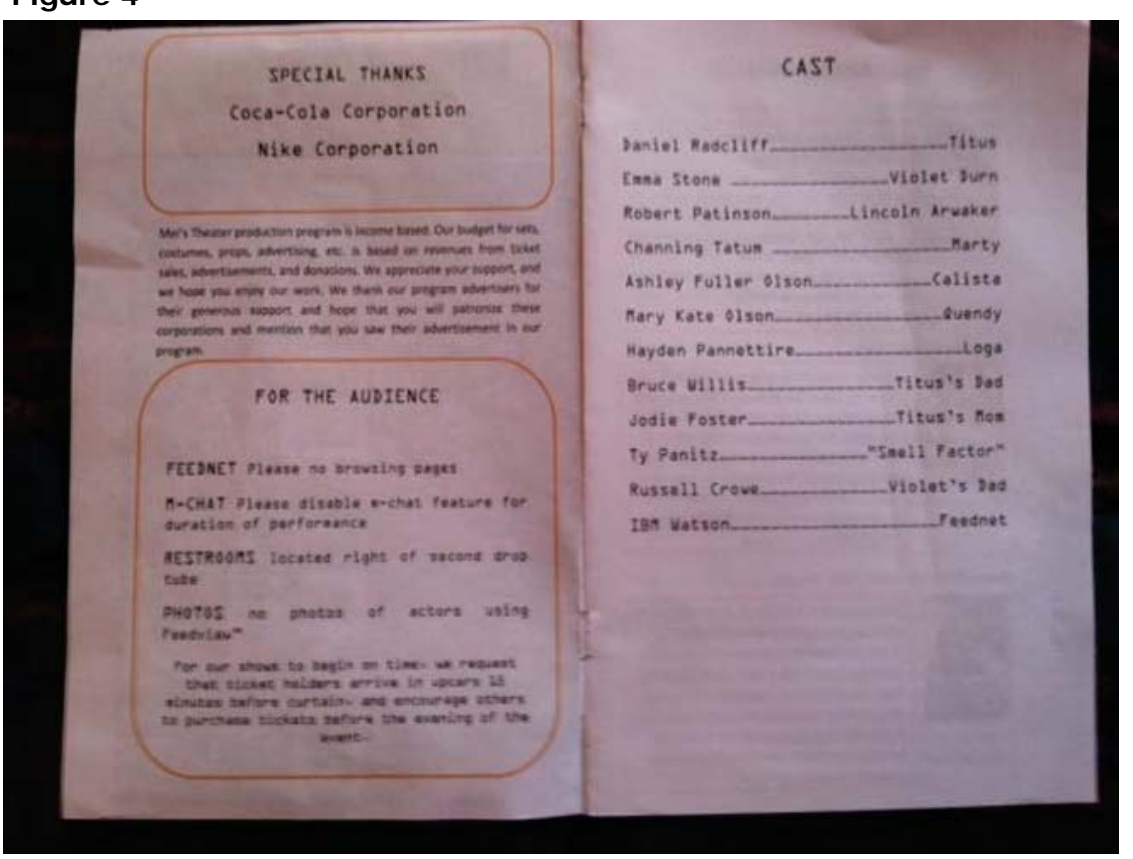

First, Mia gives special thanks to "Coca-Cola Corporation" and "Nike Corporation" because they are large corporations that we see advertised on a daily basis. This mirrors the theme of consumerism in the text. More importantly, Mia provides some instructions "for the audience" on that first page that also mirror what occurs in the text. She first writes "Feednet" and next to this states "Please no browsing pages." In the text, the feednet constantly provides individuals with pages and pages of information based on what they are doing or seeing. Mia clearly understands this concept, and hopes that the individuals at her play can basically turn off their feeds so that they don't receive information throughout the play.

Mia also asks that the audience members "please disable m-chat feature for duration of performance." In Feed, the m-chat represents the ability to communicate with other members through the feed, which Mia does not want to occur during the show. This constantly occurs in the novel, and the fact that Mia wants the audience to disable the chat feature suggests that she understands this is a function that is always on, and that it's an important form of communication, but one not acceptable during a performance. Mia's directives are a strong connection between the behaviors one would want in a theater, and tie in with the text. 


\section{Multimodal Projects That Greatly Used Technology}

When I announced the project to the students, many thought that the multimodal project required the use of technology. While it was not necessary to use technology, one student, Liz, took full advantage of digital tools and created a YouTube video that summarized and analyzed the text. The untitled video opened with the cover of the text followed by the statement, "The beginning of a new love for Violet and Titus." The subsequent image was of a young man and woman lovingly reclining on a hammock. The next title, however, continued with the statement “...didn't last as long as Violet had hoped. She was heartbroken." The video then shared statements and images that share how corporations are ruining the world. All of this occurs while the Brad Paisley song, "Welcome to the Future," played. It is very interesting that Liz chose to focus on the love story aspect of the text, as many of her classmates argued that this was not a love story, but a story of a brave young woman who fights consumerism.

\section{“It Truly Generated Much Different Thinking"}

On the due date, I had students set up their projects around the classroom so that they could take a gallery walk and look at what the others had created. I asked them to take note of at least three of the projects that they felt interpreted the literary elements clearly. I also asked them if they noticed any unique elements that were interpreted that they may not have considered and to consider the different ways some of the repeated elements were interpreted. This led to a final class discussion about the text. I then had students share some of their thoughts from their rationales, specifically how thinking multimodally shaped their thinking about the text. Below are some of the student responses:

- " “...it proved to be an interesting way to look at the events of the book..."

- "Multimodal format is a way to express your thoughts through something other than a paper, something more exciting."

- "I am not worried about what others are doing because I know that the way I picture or express my thoughts is completely different than how someone else may picture or express their thoughts."

- "...t made you look deeper into the characters and the plot. It made me realize that you don't have to like the story to understand it."

- "I psyched myself out just because I had such a creative plan and I did not think it was going to work. Once I started working on the project I really got the hang of it and got the ball rolling on how this project was going to turn out."

- "I chose to show my elements through caricatures because they allow you to express emotion through a meaningful, light-hearted drawing."

- "I chose to use pictures because I am a visual learner and a lot of people can relate to this."

- $\quad$ Thinking in a new way like this...it truly generated much deeper thinking and made me reflect a lot more on the reading and task at hand."

The trends in the student responses suggest that the project was engaging, which is something that benefits the student because she or he will be more focused on the work. I was also pleased to learn that several students thought creatively, thought more deeply about the text, and even enjoyed the assignment. Students were proud to show off their work in the gallery walk and many talked about how much time they invested in the project. The students also contributed greatly in the class discussion, comparing and contrasting some of the literary elements that they and their classmates described and analyzed. They went beyond discussing plot, setting, and character and talked in detail about the multiple themes, symbols, and motifs and other literary elements in the text and engaged in a dynamic whole class discussion that looked at the complexity of the text rather than having a surface- 
based response to the text. In essence, the students discussed elements quite deeply as they talked about character motivation, made inferences, related to the text, and discussed elements more thoroughly than they might have if they had written a paper. Because each student analyzed six elements, the gallery walk and discussion covered a wide variety of elements. Students were now comfortable with analyzing an element of the text, which would enable them to focus more deeply on a singular element in the future. They thought critically about multiple elements and their purpose in the text.

\section{Multimodality in Other Disciplines}

I chose to do a multimodal project in the literature class because I feel that this is a class that focuses so much on the linguistic mode, while other subject areas tend to automatically incorporate other modes. For instance, in science courses, students sometimes conduct experiments or look at images and graphs. In History courses, students view maps, photos and documents. This doesn't mean that other disciplines can't benefit from multimodal assignments, though.

Instructors in other courses can always invite students to create multimodal artifacts such as maps or images to understand a concept in science, Facebook profiles of historical figures and their relationships to others to further explore history, or mini-documentaries of mathematicians. In fact, it's common in elementary and even middle school to create

When the students are creating the multimodal artifacts, not only are they engaged, but they are given a sense of agency because they are choosing how to represent the information that they are learning.

projects that use multiple modes, but it's interesting that this doesn't occur as often in secondary schooling or higher education. When the students are creating the multimodal artifacts, not only are they engaged, but they are given a sense of agency because they are choosing how to represent the information that they are learning. There is also a lot of cognition as they build their artifacts. They are constantly thinking about the content.

I strongly suggest that instructors who incorporate multimodal assignments require that students write a rationale justifying their choices of modes and representation. This not only provides evidence of their thinking, but it holds students accountable for their choices, their thinking, and their understanding of the content. I also suggest that multimodal projects are shared with the whole class, so that students can gain an understanding of the content from a classmate's perspective.

\section{Conclusion}

I've always been a fan of multimodal expression because when the sender of the message has more modes to use, she or he has more ways to communicate. I jokingly give the example in class that I gesture a lot when I try to convince my students of something, and that this is a clear example of how using a mode beyond language aids me in explicitly making a point. The students were quite invested in the project, and rather than focusing on just one literary element, they were forced to re-read and review the text in order to analyze multiple literary elements. This is great scaffolding, because future assignments require them to write more deeply about singular elements. The Multimodal Analysis of Literary Elements in 'Feed' in a sense is practice for looking at multiple literary elements within the text so that in the future, students will have more elements to choose from when they produce future analyses of a literary text. 


\section{References}

Anderson, M. T. (2002). Feed. Cambridge, MA: Candlewick Press.

Bailey, N. M. (2009). It makes it more real: Teaching new literacies in a secondary English classroom. English Education, 41, 207-234.

Dalton, B., \& Proctor, C. P. (2008). The changing landscape of text and comprehension in the age of new literacies. In J. Coiro, M. Knobel, C. Lankshear, \& D. J. Leu (Eds.), Handbook of Research on New Literacies (pp. 297324). New York, NY: Routledge.

Kress, G., \& Van Leeuwen, T. (1996). Reading images: The grammar of visual design. London, England: Routledge.

Leu, D. J., \& Kinzer, C. K. (2000). The convergence of literary instruction with networked technologies for information and communication. Reading Research Quarterly, 35(1), 108-127.
Pierce, C. P. (1934). Collected papers: volume V. Pragmatism and pragmaticism. Cambridge, MA: Harvard University Press.

Rozema, R. (2007). The book report, version 2.0: podcasting on young adult novels. Journal of Adolescent and Adult Literacy, 97(1), 31-36.

Street. B. V. (1984). Literacy in theory and practice. Cambridge, MA:

Cambridge University Press.

Suhor, C. (1984). Towards a semioticbased curriculum. Journal of Curriculum Studies, 16(3), 247-257.

Vygotsky, L. (1986). Thought and language. (A. Lozulin, Trans.).

Cambridge, MA: The MIT Press.

Tim Oldakowski is an Assistant Professor in the English Department at Slippery Rock University in Slippery Rock, PA where he teaches both English Education methods courses and English courses. Tim's research focuses on multimodal instruction and assessment. He is an active member of NCTE, the National Council of Teachers of English and his work has been published in the Journal of Media Literacy Education and in the International Society for Technology in Education sponsored text Teaching Literacy in the Digital Age: Inspiration for All Levels and Literacies edited by Mark Gura. You can follow Tim's blog, Oldakowski's Educational Stuff, which focuses on technology, new literacies and multimodality in ELA at www.oldakowskiseducationalstuff. blogspot.com. 